\title{
JUSTIÇA E DIREITO: AS CORTES SUPREMAS DE BRASIL E ARGENTINA FRENTE AOS CRIMES DAS DITADURAS DE SEGURANÇA NACIONAL ${ }^{1}$
}

\section{Patrícia da Costa Machado ${ }^{2}$}

\begin{abstract}
Resumo
O presente artigo analisará comparativamente as características de alguns elementos fundamentais do posicionamento das Cortes Supremas de Brasil e Argentina no que diz respeito a responsabilização penal dos crimes cometidos pelas ditaduras. O debate presente nas decisões dos fallos Arancibia Clavel, Símon, Mazzeo e na Arguição de Descumprimento de Preceito Fundamental n. 153 decorrem da utilização de métodos ilegais e terroristas por parte dos Estados durante as Ditaduras de Segurança Nacional. Ambas as ditaduras foram implementadas dentro de um marco comum, decorrente do contexto da Guerra Fria e da aplicação da Doutrina de Segurança Nacional. Suas diferenças, embora relevantes, não afastam as similitudes das experiências no que diz respeito à massiva violação dos direitos humanos, em decorrência da perseguição dos "inimigos internos" dos regimes. Por esse motivo, analisaremos brevemente a estrutura das Cortes Supremas e os casos paradigmáticos julgados pelas instâncias superiores de cada país, buscando compreender as diferenças entre os entendimentos jurisprudenciais.
\end{abstract}

Palavras-chave: Ditaduras. Brasil. Argentina. Supremas Cortes. Crimes de lesa humanidade.

\begin{abstract}
This paper is going to analise in comparance the characteristics of some key elements in the Supreme Courts of Brazil and Argentina with regard to criminal responsibility for crimes committed by dictatorships. The debate witihin the decisions in three cases: Arancibia Clavel, Simón and Mazzeo, as well in the Arguição de Descumprimento de Preceito Fundamental n. 153, that shows that they derive from the use of illegal methods and terrorists by States during the Homeland Security Dictatorships. Both dictatorships were implemented within a common framework, deriving from the context of the Cold War and the implementation of the National Security Doctrine. Their differences, though relevant, do not rule out the similarities of experiences with regard to massive human rights violations as a result of the persecution of "internal enemies" of the schemes. For this reason, briefly analyze the structure of Supreme Courts and the paradigmatic cases judged by the higher courts of each country, trying to understand the differences between the jurisprudential understanding.
\end{abstract}

Keywords: Dictatorships. Brazil. Argentina. Supreme Courts. Crimes against humanity.

\section{Resumen}

Este artículo analisará comparativmente las características de algunos elementos clave de la posición de las Cortes Supremas de Brasil y Argentina con respecto a la responsabilidad penal por los crímenes cometidos por las dictaduras. El debate en las decisiones de Arancibia Clavel Fallos, Simón, Mazzeo y en la Arguição de Descumprimento de Preceito Fundamental n. 153, derivados de la utilización de métodos y terroristas ilegales por los Estados durante las Dictaduras de Seguridad Nacional. Ambas dictaduras fueron implementadas dentro de un marco común, derivada del contexto de la Guerra Fría y la aplicación de la Doctrina de Seguridad Nacional. Sus diferencias, aunque relevante, no se descartan las similitudes de las experiencias en materia de violaciónes masivas de los derechos humanos como resultado de la persecución de los "enemigos internos" de los esquemas. Por esta razón, analizar brevemente la estructura de las Cortes Supremas y los casos paradigmáticos juzgados por los tribunales superiores de cada país, tratando de entender las diferencias entre el entendimiento jurisprudencial.

Palabras clave: Dictaduras. Brasil. Argentina. Cortes Supremas. Crímenes de Lesa Humanidad.

\footnotetext{
${ }^{1}$ DOI deste artigo: 10.5380/recp.v6i2.42649.

2 Mestre em História pela Universidade Federal do Rio Grande do Sul (UFRGS). Email: patydcm@hotmail.com.
} 


\section{INTRODUÇÃO}

Entre os anos de 2005 e 2007, a Corte Suprema de Justicia de la Nación Argentina (CSJN) julgou três recursos (referentes aos casos Simón, Arancibia Clavel e Mazzeo) cujas decisões serviram de suporte às modificações sociais e jurídicas que a Argentina presenciou - e ainda presencia- no que diz respeito aos julgamentos dos crimes cometidos na última ditadura civilmilitar que assolou o país entre os anos de 1976 e 1983. Nestas decisões, a mais alta instância do Judiciário argentino declarou inconstitucionais as leis de impunidade (Lei do Ponto Final e Lei da Obediência Devida), e os indultos concedidos pelo Presidente Carlos Menem em 1990, por entender que estes impediam a investigação e o julgamento de crimes de lesa humanidade.

Alguns anos depois, em 2010, o Supremo Tribunal Federal (STF), máxima instância do Judiciário brasileiro, julgaria improcedente a Arguição de Descumprimento a Preceito Fundamental (ADPF) n $n^{\circ} .153$, que contestava o artigo $2^{\circ}$ da Lei da Anistia (Lei no $\left..6 .683 / 79\right)$, que anistiou os crimes conexos aos crimes políticos (ou seja, os crimes cometidos pelos agentes da ditadura). Os sete ministros que votaram pela improcedência entenderam que a interpretação da anistia recíproca, embora contrária à legislação internacional de proteção aos direitos humanos, devia ser mantida, tendo em vista o acordo político estabelecido naquele contexto de redemocratização e "pacificação" social.

Entre as décadas de 1960 e 1980, os países do Cone Sul (Argentina, Brasil, Chile e Uruguai) vivenciaram Ditaduras de Segurança Nacional. As diferentes experiências vividas em cada uma dessas nações possuem alguns elos em comum: a aplicação da Doutrina de Segurança Nacional (DSN) ${ }^{3}$, o que inclui a perseguição do “inimigo interno", a suspensão de direitos e garantias fundamentais, a tomada do poder pelas Forças Armadas, o consequente estabelecimento do Terrorismo de Estado (TDE) e, por fim, a aprovação de algum tipo de anistia ao fim desses regimes.

\footnotetext{
${ }^{3}$ Doutrina de Segurança Nacional (DSN), elaborada pelos Estados Unidos no pós-guerra, parte do princípio de que a nação, com seus valores, símbolos e deveres estava ameaçada por forças subversivas. A DSN considera como inimigo qualquer forma de pensamento que procura examinar mais atentamente a realidade social fora dos parâmetros daquela doutrina. Para a doutrina da Segurança Nacional são dois os tipos de inimigos: o interno e o externo. O inimigo externo fica consignado quando uma nação invade a outra; inimigo interno deve ser observado através da "ação indireta" dos comunistas, que, segundo a doutrina, agem nos movimentos sociais da classe trabalhadora, entre estudantes, intelectuais, Igrejas, promovendo a subversão da ordem e divulgando a necessidade de guerra revolucionária.
} 
Tais ditaduras tiveram temporalidades diferentes não apenas quanto ao momento dos golpes, mas também em seus processos de transição para a democracia. Como se sabe, dentre os quatro países do Cone Sul, o golpe no Brasil foi o primeiro a instaurar uma ditadura de segurança nacional, em 1964. Chile e Uruguai teriam suas democracias derrubadas nove anos depois, em 1973 e, por último, a Argentina sofreria o golpe mais violento de sua história, em 1976. A redemocratização nesses países também ocorreu em momentos diversos da década de 1980, com questões internas singulares. Diferentes, também, seriam os mecanismos utilizados para o retorno democrático, embora todos compartilhem de elementos comuns, especialmente a aprovação de leis de anistia.

Tendo diferentes designações, as leis aprovadas nesses países visavam um mesmo objetivo: impossibilitar a responsabilização de militares e civis pelas inúmeras violações aos direitos humanos cometidas durante as ditaduras. O discurso de "virar a página e olhar para o futuro" esteve presente em todos países e foi usado para propagar a ideia da pacificação nacional, único meio que permitiria a solidificação democrática.

No Brasil, o Movimento pela Anistia teve início ainda na década de 1970, durante o governo de Ernesto Geisel. Em 1979, já no governo de João Figueiredo, foi encaminhado ao Congresso (ainda limitado pelas imposições da ditadura, com a nomeação de senadores biônicos e com um sistema político bipartidário) um projeto de anistia que, após inúmeras discussões e emendas, foi aprovado nos moldes pretendidos pela ditadura, ou seja, uma anistia restrita, que isentou os crimes cometidos pelos agentes da repressão. Assim, surgiu a Lei $n^{\circ} 6.683 / 79$, que ficou conhecida como Lei da Anistia e que está em vigência até os dias atuais ${ }^{4}$.

$\mathrm{Na}$ Argentina, os militares promulgaram, em setembro de 1983, a Ley de Pacificación Nacional, que anistiou todos os crimes cometidos durante a ditadura. O primeiro presidente eleito democraticamente, Raul Alfonsín, com forte respaldo social, anulou referida lei dias após sua posse, em dezembro do mesmo ano, e nomeou uma Comissão que investigaria os desaparecimentos ocorridos no período, que resultou no Informe Nunca Más. Também instaurou o julgamento das Juntas Militares que governaram o país, concluído em 1985, com a condenação da maioria de seus membros. Entretanto, em 1986 e 1987, pressionado por

\footnotetext{
${ }^{4}$ Sobre o contexto histórico da ditadura e da transição, ver MOREIRA ALVES, 1987; DREIFUS, 1981; FICO, 2012; FERREIRA, 2014. Importante também a produção sobre justiça de transição no Brasil: MAZZUOLI; GOMES, 2009; DA SILVA FILHO, José Carlos Moreira, 2015 e os artigos publicados na revista da Comissão da Anistia.
} 
forças políticas e por insurreições militares, dentro de um quadro de instabilidade econômica, Alfonsín encaminhou ao Congresso duas leis que ficariam conhecidas como leis de impunidade: a Lei de Ponto Final ${ }^{5}$ e a Lei de Obediência Devida ${ }^{6}$ Por fim, em 1989 e 1990, o então presidente Carlos Menem, indultou os membros das Juntas que haviam sido condenados em 1985, estabelecendo a impunidade na Argentina ${ }^{7}$ que duraria toda década de 1990 e parte dos anos $2000^{8}$.

Ao analisarmos as condições internas e externas que possibilitaram a instauração de golpes e ditaduras em ambos os países, percebemos que as diferenças são consideráveis, tanto no que diz respeito às características das ditaduras e à maneira que ambas chegaram ao fim, quanto às decisões políticas dos governos democráticos que seguiram as transições de regime. Podemos apontar que a diferença entre transições pactuadas e por ruptura ${ }^{9}$ explicam de maneira parcial a diferença nos governos democráticos que sucederam os militares. Enquanto na Argentina a questão dos desaparecimentos e dos julgamentos das Juntas esteve presente já nas eleições presidenciais de 1983, sendo concretizadas com a eleição de Raul Alfonsín, no Brasil essa questão já estava decidida desde 1979, não tendo sido revista após o retorno à democracia. Entretanto, a trajetória de ambos os países na década de noventa se assemelha em muitos pontos. A chegada ao poder de presidentes que implementaram uma agenda neoliberal (Menem e FHC) e o retrocesso na área da atuação do Judiciário no tema

\footnotetext{
5 A Lei no 23.492, chamada Lei de Ponto Final, foi promulgada na Argentina em 24 de dezembro de 1986, durante a presidência de Raul Alfonsín, estabelecendo a paralisação dos processos judiciários contra os autores das detenções ilegais, torturas e assassinatos que ocorreram na etapa de ditadura civil-militar.

${ }^{6}$ A Lei no 23.521, chamada Lei de Obediência Devida, foi uma disposição legal ditada na Argentina em 4 de junho de 1987, durante o governo de Raul Alfonsín, que estabeleceu uma presunção de que os feitos cometidos pelos membros das forças armadas durante a guerra suja e o Processo de Reorganização Nacional não eram puníveis por haver agido em virtude de obediência devida.

${ }_{7}^{7}$ Os indultos são uma série de dez decretos sancionados, em 1989 e 1990, pelo presidente Carlos Menem, indultando civis e militares que cometeram crimes durante a ditadura civil-militar, incluindo os membros das Juntas Militares, condenados em 1985. Cerca de 1.200 pessoas foram beneficiadas.

${ }^{8} \mathrm{Na}$ Argentina, a produção sobre a temática é extremamente rica, tendo em vista o atual estágio dos julgamentos naquele país. Dentre as obras mais recentes, que analisam os impactos da retomada dos processos e o desenvolvimento das megacausas, destacamos ANDREOZZI, 2011; AGEITOS, 2011; LORENZETTI, 2011; LANZILOTTA; FEIJOO, 2014. Sobre o contexto histórico da ditadura e da transição, ver NOVARO, 2008; NOVARO; PALERMO, 2007.

${ }^{9}$ Quando a liberalização do regime autoritário conduz à negociação a transição dá-se sem grande violência, sem mudanças relevantes nos tecidos sociais e sem criar grande instabilidade, havendo mais garantias de êxito. É a chamada transição pactuada - um acordo entre todos os grupos que ascendem ao novo regime, como o caso brasileiro. A segunda transição será aquela em que há queda ou derrube do regime, por ruptura. Neste caso, segundo Huntington, a democratização resulta do enfraquecimento do governo e do fortalecimento da oposição. A Argentina é um exemplo de transição por ruptura, tendo em vista o desgaste do regime, principalmente após a derrota na Guerra das Malvinas.
} 
mostram que as transições não explicam satisfatoriamente a diferença acentuada que se concretizou a partir dos anos 2000.

Enquanto na Argentina o caminho levou, a partir de 2004, à anulação, por parte da Corte Suprema, de todos os dispositivos que representassem obstáculos ao julgamento dos crimes da ditadura, no Brasil, o Supremo Tribunal Federal, em 2010, julgou improcedente uma ação ajuizada pela Ordem dos Advogados do Brasil (OAB) e considerou a Lei da Anistia fruto de um acordo político e, por consequência, impassível de revisão. Apesar da condenação do Estado brasileiro na Corte Interamericana de Direitos Humanos $(\mathrm{CIDH})^{10}$ no caso da Guerrilha do Araguaia, em dezembro do mesmo ano, o cenário não teve modificações significativas. Até o momento em que essa pesquisa é iniciada, nenhum repressor foi levado ao banco dos réus e condenado.

Este artigo visa compreender e analisar, de maneira geral, a discrepância entre os entendimentos das Supremas Cortes de países assolados por Ditaduras de Segurança Nacional $^{11,}$ abordando como e por que as Supremas Cortes de Brasil e Argentina consolidaram entendimentos tão diversos no tocante aos julgamentos de crimes de lesa humanidade cometidos no período das ditaduras. Para tanto, analisaremos o uso da interpretação das leis de anistia (e similares) frente ao direito internacional dos direitos humanos.

\section{PASSADOS EM COMUM, PRESENTES DISTINTOS: A ATUAÇÃO DAS SUPREMAS CORTES ARGENTINA E BRASILEIRA FRENTE AOS CRIMES DAS DITADURAS}

Primeiramente, importante salientar que Brasil e Argentina possuem um Poder Judiciário estruturado de maneira similar: ambos possuem divisões por competência em razão da matéria em seu judiciário (justiça federal, justiça estadual ou provincial, etc) e ambas seguem o padrão do duplo grau de jurisdição, presente na maioria dos países ocidentais. Ambos os países possuem, igualmente, um órgão responsável pela fiscalização e interesse da

\footnotetext{
${ }^{10}$ A Corte Interamericana de Direitos Humanos (CIDH) é um órgão judicial autônomo que tem sede em San José (Costa Rica), cujo propósito é aplicar e interpretar a Convenção Americana de Direitos Humanos e outros tratados de Direitos Humanos. Faz parte do chamado Sistema Interamericano de Proteção aos Direitos Humanos. Argentina, Brasil, Chile e Uruguai são signatários da Convenção e se sujeitam à jurisdição da Corte. 11 Para fins deste trabalho, consideramos a nomenclatura "ditadura civil-militar" e "ditadura de segurança nacional", embora cientes da existência de extenso debate conceitual acerca da definição dos regimes instaurados na região.
} 
sociedade (o Ministério Público), sendo a diferença mais palpável que o MP argentino possui duas vertentes (a Fiscalia, responsável pelas ações penais, e o MP da Defensoria, responsável pelo assessoramento das pessoas de baixa renda, função que no Brasil é exercida pelas Defensorias Públicas). Ademais, as Cortes Supremas seguem o modelo estadunidense de Corte política: as nomeações para seus integrantes são feitas pelo Poder Executivo e sabatinadas pelo Poder Legislativo.

A ambas as Cortes cabe a última palavra no que diz respeito a interpretação e aplicação das Constituições pátrias. Quaisquer leis (sejam elas federais ou estaduais/provinciais) ou decisões jurídicas que violem preceitos constitucionais podem ser levadas, via recursos ou ações originárias, à apreciação do tribunal superior.

Em termos concretos, o Supremo Tribunal Federal atuou numa ação originária, no caso a Arguição de Descumprimento de Preceito Fundamental, ajuizada pela Ordem dos Advogados do Brasil (órgão de representação da advocacia brasileira), e deveria se pronunciar sobre a constitucionalidade de um dispositivo da Lei da Anistia. Sua decisão, portanto, teria efeito para todos os casos envolvendo crimes anistiados pela referida Lei. A Corte Suprema de la Nación, por sua vez, atuou como última instância em três recursos, provenientes de três processos que já haviam sido julgados pela primeira instância e pelos tribunais inferiores. Através do julgamento de casos específicos, foi levada ao tribunal superior argentino a questão da constitucionalidade de três questões: a imprescritibilidade dos crimes, considerados como crimes contra a humanidade (Caso Arancíbia Clavel); a inconstitucionalidade das Leis de Ponto Final e Obediência Devida (Caso Simón) e a inconstitucionalidade dos indultos dados por Carlos Menem em 1989/1990 (Caso Mazzeo). Através da análise de processos específicos e concretos, os ministros argentinos analisaram essas questões.

Essa diferença é relevante uma vez que demonstra que as instâncias inferiores do judiciário argentino continuavam se pronunciando frente a ações que envolviam crimes cometidos durante a ditadura, apesar das leis e dos indultos. Isso ocorria em razão das brechas das leis de impunidade (o que fica evidenciado no caso Simón) e da eficaz realização do controle de convencionalidade ${ }^{12}$ exercidos pelos juízes de primeira instância, que aplicavam os tratados internacionais em consonância com a Reforma Constitucional de 1994

${ }^{12}$ Trata-se da aferição da compatibilidade entre tratados e normais internacionais e as Constituições e legislação nacionais. 
(Pacto de Olivos). No Brasil, contudo, esse controle raramente foi (e ainda é) exercido. Nenhum caso envolvendo a matéria chegou via recurso ao Supremo pois em regra, os juízes de primeira instância e os tribunais sequer recebiam as denúncias, aplicando a Lei da Anistia sem analisar as questões de direito internacional.

A mais alta instância do Poder judiciário do Brasil, como dito, é o Supremo Tribunal Federal (STF). Sua função institucional fundamental é de servir como guardião da Constituição Federal de 1988, apreciando casos que envolvam lesão ou ameaça a ela. O STF acumula competências típicas de Suprema Corte (tribunal de última instância) e Tribunal Constitucional (que julga questões de constitucionalidade, independentemente de litígios concretos).

Durante a ditadura, o Supremo Tribunal Federal foi vital para a manutenção do regime, papel que ficou estabelecido de maneira contundente logo após o golpe, com a participação do presidente da Corte, ministro Álvaro Moutinho Ribeiro da Costa, à posse inconstitucional - de Ranieri Mazzili no cargo de Presidente. O presidente do STF também recebeu Castelo Branco (primeiro presidente-ditador do Brasil) dias após sua chegada ao governo, e acusou João Goulart pela situação do país, declarando que independente de circunstâncias políticas, não cabia à Justiça tomar posição sobre a situação, e que em momentos de crise, era necessário fazer sacrifícios constitucionais em nome da democracia. Portanto, o STF se mostrou disposto a colaborar com a ditadura desde o princípio.

Ao longo da ditadura, contudo, o STF sofreu várias intervenções. O Ato Institucional n. 2 aumentou o número de ministros para 16, levando à indicação de Ministros teoricamente mais alinhados ao regime. Entre 1964 a 1985, a ditadura nomeou 32 ministros. No início de 1969, o STF foi atingido novamente em sua própria formação. Em fevereiro de 1969, com o Ato Institucional n. 6, o Costa e Silva reduziu o número de magistrados de 16 para 11 e transferiu todos os delitos contra a segurança nacional ou as forças armadas para a jurisdição do Supremo Tribunal Militar e dos tribunais militares de categoria inferior. Nesse contexto, três ministros foram forçados a se aposentar: Victor Nunes Leal, Hermes Lima e Evandro Lins e Silva. Além disso, o presidente do Tribunal, Ministro Gonçalves de Oliveira, renunciou em sinal de protesto.

Entretanto, é necessário apontar que embora atingido diretamente pela quebra na separação de poderes, decorrente da concentração e centralização focada no Executivo, a mais alta instância do Judiciário brasileiro não foi uma "vítima" do regime. Nesse sentido, 
Oscar Vilhena Vieira aponta que o período da transição é um período marcado por um grande silêncio por parte do Supremo e dos tribunais em geral, que deveriam, teoricamente, trabalhar visando a reconstrução do Estado de Direito e da democracia. Uma vez revogados os atos institucionais e demais amarras institucionais, seria de se esperar uma atuação forte e incisiva por parte do Judiciário. Entretanto, isso não ocorreu.

A estrutura do Supremo foi mantida pela Constituição de 1988. Suas atribuições foram ampliadas, redefinindo o papel do Tribunal no sistema constitucional e político do país. Com a ampliação de novos atores legitimados para apresentar ações de inconstitucionalidade, surge um novo campo de conflitos constitucionais, onde os tribunais necessitam intervir ${ }^{13}$. A Constituição manteve também a formação estabelecida no Ato Institucional n. 6, mantendo-se, assim, a formação de 11 integrantes, que são escolhidos entre cidadãos com mais de trinta e cinco anos e menos de sessenta e cinco anos de idade, com "notável saber jurídico e reputação ilibada", nomeados pelo Presidente da República. Importante salientar que este critério de escolha política para o cargo mais elevado do Poder Judiciário é altamente questionado (PEGORARO, 2011)

Atualmente, a Corte Suprema do país é composta apenas por ministros indicados por presidentes civis: Celso de Mello (indicado por José Sarney), Marco Aurélio Melo (indicado por seu primo, Fernando Collor de Melo), Gilmar Mendes (indicado por Fernando Henrique Cardoso), Ricardo Lewandowski, Carmen Lúcia, José Toffoli Dias (indicados por Luiz Inácio Lula da Silva), Rosa Weber, Teori Zavascky, Luiz Fux e Luis Roberto Barroso (indicados por Dilma Rousseff). Devido a aposentadoria compulsória de Carlos Britto, o Executivo indicou, em abril de 2015, o nome de Luiz Edson Fachin.

Desde os anos 90, diversas ações foram ingressadas nas mais diversas instâncias do Judiciário brasileiro visando responsabilizar agentes do estado que violaram os direitos humanos, quase sempre esbarrando na Lei $6.683 / 79$, que anistiou todos os crimes políticos cometidos entre 1946 e 1979, incluindo os crimes conexos aos crimes políticos (ou seja, os crimes cometidos pelos repressores).

\footnotetext{
13 O artigo 103 da Constituição legitima o Presidente da República, as mesas do Senado e do Congresso, das Assembleias Legislativas estaduais, os governadores dos Estados, o Procurador Geral da República, o Conselho Federal da Ordem dos Advogados do Brasil, as confederações sindicais e as entidades de classe de âmbito nacional a proporem ações constitucionais no Supremo Tribunal Federal. Isso, somada a criação do Superior Tribunal de Justiça (STJ), que incorpora funções que eram do STF, transforma a corte em tribunal predominantemente constitucional.
} 
Dentre as diversas ações, a de maior relevância foi a Arguição de Descumprimento de Preceito Fundamental (ADPF), no 153, ajuizada pelo Conselho Federal da Ordem dos Advogados do Brasil (OAB) em 2008. O argumento jurídico elaborado pela OAB seria que a norma que concedeu anistia a vários agentes públicos responsáveis, entre outras violências, pela prática de homicídio, desaparecimento forçado, tortura e abusos sexuais contra opositores políticos, violaria frontalmente diversos preceitos da Constituição. Alegava a $\mathrm{OAB}$, entre outros argumentos, que o dispositivo contestado (parágrafo $1^{\circ}$ do artigo $1^{\circ}$ da Lei nº 6.683/79) não teria sido objeto de recepção pela Constituição Federal de 1988, que reputa o crime de tortura como insuscetível de anistia ou graça. Além disso, alegou a Ordem que a Corte Interamericana de Direitos Humanos já teria decidido, em ao menos cinco casos, pela nulidade da autoanistia criminal decretada por governantes.

Importante destacar que pela primeira vez uma ação perante o STF com efeito vinculante foi processada simultaneamente a um processo internacional com objeto semelhante em curso perante a Corte Interamericana de Direitos Humanos. Quando do julgamento da ADPF nº. 153, em 28.04.2010, já havia sido proposta a demanda da Comissão Interamericana de Direitos Humanos à Corte de San Jose (caso Gomes Lund e outros x Brasil) ${ }^{14}$, sem julgamento final. Tal fato, contudo, não ocasionou nenhum pedido de adiamento por parte dos Ministros, para que pudessem verificar os argumentos da futura sentença da Corte.

Ajuizada em 21 de outubro de 2008, em abril de 2010, o Supremo Tribunal Federal decidiu, por maioria de votos, pela improcedência da ação. O relator, Ministro Eros Grau analisou os argumentos jurídicos apontados pela $\mathrm{OAB}$ e afastou a inconstitucionalidade do texto legal.

O direito internacional dos direitos humanos no presente caso foi solenemente ignorado pelos Ministros. Os votos dos ministros Marco Aurélio Mello, Carmen Lúcia e Ellen Gracie, sequer mencionaram tratados internacionais ou jurisprudência, calcando seus votos na ideia da Lei da Anistia como fruto do acordo entre as partes. Gilmar Mendes, por sua vez, também não mencionou os direitos humanos internacionais e defendeu que os crimes da ditadura não poderiam ser considerados imprescritíveis.

Os dois ministros que votaram pela procedência da ação, Ricardo Lewandowski e Carlos Britto, fundamentaram suas decisões com argumentos distintos. Lewandowski

\footnotetext{
${ }^{14}$ Em agosto do mesmo ano de 2010, a Corte Interamericana de Direito Humanos (CIDH) publicou sentença no caso Julia Gomes Lund versus Brasil, que condenou o Brasil por não ter punido os responsáveis pelas mortes e pelos desaparecimentos ocorridos na Guerrilha do Araguaia.
} 
analisou a ausência de conexão entre crimes comuns e crimes políticos e foi além, defendendo a necessidade de afastar a incidência da Lei de Anistia aos agentes do Estado, como se verifica no seguinte trecho de seu voto:

O mesmo se diga quanto ao delito de tortura. Embora este crime tenha sido formalmente tipificado apenas a partir da Lei 9.455/97, a sua prática, evidentemente, jamais foi tolerada pelo regime de exceção. Não bastasse a previsão da lei penal ordinária, que sancionava, dentre outros crimes, as lesões corporais e os maus-tratos, a Lei 4.898/65 definia - e ainda define, pois continuam em vigor $-\mathrm{em}$ seus artigos $3^{\circ}$ e $4^{\circ}$, as hipóteses de abuso de autoridade, arrolando, dentre elas, o atentado à incolumidade física ao indivíduo e de submissão de pessoa sob sua guarda ou custódia a vexame ou constrangimento não autorizado em lei.

Ainda que se admita, apenas para argumentar, que o país estivesse em uma situação de beligerância interna, ou, na dicção do Ato Institucional 14/1969, enfrentando uma "guerra psicológica adversa", "guerra revolucionária" ou "guerra subversiva", mesmo assim os agentes estatais estariam obrigados a respeitar os compromissos internacionais concernentes ao direito humanitário, assumidos pelo Brasil desde o início do século passado ${ }^{15}$.

Embora tenha votado pela parcial procedência da ação, Lewandowski considerou desnecessário aprofundar a análise do direito internacional por entender que os delitos cometidos pelos agentes da repressão seriam crimes comuns, tipificados na legislação interna (Código Penal). Entretanto, foi o único voto que mencionou a posição da Corte sobre o dever de investigar, processar e punir criminalmente violações aos direitos humanos, dever esse compatibilizado com a Constituição.

Embora alguns Ministros tenham citado experiências dos países vizinhos (em especial Argentina e Chile), nenhum voto analisou o fato, por exemplo, de que a grande mudança ocorrida na Argentina decorre, em larga instância, da interpretação dada à legislação interna do país no que diz respeito à recepção do direito internacional dos direitos humanos. Todas as mudanças que possibilitaram a retomada dos julgamentos naquele país passam por isso. Os três processos que anularam as leis de impunidade e os indultos (caso ArancibiaClavel, caso Simón e caso Mazzeo) foram todos baseados em argumentos de direito internacional. $\mathrm{O}$ acórdão da $\mathrm{ADPF} \mathrm{n}^{\circ}$ 153, portanto, deixou evidente a enorme resistência por parte da mais alta instância do Judiciário brasileiro em abandonar a ideia de soberania absoluta do Estado, o que consolida uma postura conservadora do STF quanto à aplicação

${ }^{15}$ Voto do Ministro Ricardo Lewandowski. p.117-118. 
de normas do direito internacional, e que ficou evidente com a prolação da sentença da Corte Interamericana de Direitos Humanos no caso Gomes Lund.

\section{CORTE SUPREMA DE JUSTICIA DE LA NACIÓN ARGENTINA E OS TRÊS CASOS PARADIGMÁTICOS: ARANCIBIA CLAVEL, SIMÓN E MAZZEO}

A Corte Suprema de Justicia de la Nación Argentina (CSJN) é o mais elevado Tribunal de justiça daquele país. Foi criada em 15 de janeiro de 1863. A CSJN, assim como sua congênere brasileira, é o último dos tribunais na hierarquia jurisdicional, ou seja, suas decisões não podem ser recorridas para nenhuma outra instância. A ela cabe o julgamento dos casos em que se põem em dúvida a constitucionalidade de leis ou de decisões dos tribunais inferiores. Segundo Leticia Barrera, a CSJN

[...] puede actuar como tribunal de primera instancia en los casos que correponden a su competencia originaria y exclusiva, conforme a lo establecido en los artículos 116 y 117 de la Constitución nacional; artículos 23 y 24, inciso I del Decreto-Ley 1285 de 1958. Por otra parte, la competencia de la Corte por vía de apelación está establecida en los artículos 116 y 117 y por normas específicas que regulan los recursos ordinarios y extraordinarios (BARRERA, 2012, p. 96).

Assim como no Brasil, a composição da Corte seria uma constante na história argentina. A Lei n ${ }^{\circ}$ 15.271, de 1958, aumentou seu número para sete, porém Juan Carlos Onganía devolveu-a para seu número original (Lei $\mathrm{n}^{\circ}$ 16.895). A Corte Suprema foi finalmente elevada em número de membros para os nove atuais pela Lei $n^{\circ} 23.774$, sendo escolhidos novos membros pelo então Presidente Carlos Menem. Em 30 de novembro de 2006, foi aprovada a Lei n. 26.183, que reduziu o número de ministros para cinco.16

Durante a década de 90, a Corte Suprema foi duramente criticada por não possuir a suficiente independência do Poder Executivo; muitos de seus membros foram acusados de compor uma "maioria automática" que sempre decidia a favor dos interesses do governo. Durante o governo do Presidente Néstor Kirchner, iniciado em 2003, todos os membros desta chamada "maioria automática" foram removidos de seus cargos por julgamento político, ou renunciaram antes que tal juízo iniciasse. O Ministro Antonio Boggiano, o último dos "automáticos", foi destituído em 29 de setembro de 2005.

\footnotetext{
${ }^{16}$ Disponível em: <http://www.infoleg.gov.ar/infolegInternet/anexos/120000124999/123154/norma.htm>. Data de acesso: 30 de julho de 2015.
} 
Desde junho de 2003, por decreto presidencial, todos os candidatos a integrar a Corte Suprema devem passar por uma etapa de exposição pública, onde o Poder Executivo deve apresentá-los nos principais meios de comunicação do país. O currículo do nomeado (ou nomeados) deve ser publicado e exposto no site do Ministério da Justiça, e pode ser discutido por ONGs, associações de Direito, universidades, organizações de Direitos Humanos, e por qualquer cidadão que assim o deseje. Após um período de três meses, o Presidente, considerando os apoios e rejeições à candidatura, está enfim habilitado para apresentar a nomeação ao Senado Federal, que deve decidir se aprova ou não o nome proposto pelo Presidente para compor a Corte - necessária a maioria de dois terços dos senadores para a referida aprovação.

A renovação da Corte Suprema de Justiça, durante os dois primeiros anos do governo de Kirchner, foi vista e é usualmente reconhecida internacionalmente como um passo positivo, que dá mais independência ao Poder Judiciário e equilíbrio da Corte, tanto ideologicamente quanto por gênero: até alguns anos antes todos os juízes eram homens, católicos e conservadores. Após essas mudanças foram indicadas Elena Highton de Nolasco e Carmem Argibay, esta última defensora doe direitos das mulheres. Eugenio Zaffaroni (o primeiro a ser designado mediante um processo público de nomeação) é um dos maiores penalistas da América Latina, tendo um posicionamento firme em relação ao uso do que ele chama "direito penal liberal".

Foi nesse contexto de modificações que a Corte julgaria três importantes recursos que mudariam o entendimento acerca da possibilidade de punir os crimes perpetrados por agentes da repressão durante a ditadura: os recursos de Arancibia Clavel, Julian Simón e Santiago Riveros.

Em 24 de agosto de 2004, a CSJN julgou um Recurso de Hecho interposto pela defesa de Enrique Lautaro Arancibia Clavel. Entre março de 1974 e novembro de 1978, Arancibia Clavel integrou uma associação ilícita chilena, a Dirección de Inteligencia Nacional (DINA), cuja atividade consistia na perseguição de opositores políticos do regime de Pinochet que se encontravam na Argentina. Ele foi acusado, entre outros crimes, de participar no atentado a bomba que provocou a morte do General chileno Carlos Prats e sua esposa Sofia Cuthbert, em Buenos Aires no ano de 1974. Foi condenado à prisão perpétua por homicídio qualificado pelo uso de explosivos e por associação ilícita, crimes previstos no Código Penal argentino (artigos 80 e 210). 
Condenado em primeira instância pelo Tribunal Oral Federal n. 6, Arancibia Clavel recorreu à Cámara Nacional de Casación Penal, que declarou a prescrição dos crimes. Dessa decisão, o governo chileno interpôs um Recurso Extraordinário à Corte Suprema, para que o tribunal superior se manifestasse sobre o caso $^{17}$.

A CSJN estabeleceu que a conduta imputada seria um crime de lesa humanidade e, por consequência, imprescritível, o que não violaria o princípio da legalidade formal frente a adesão a Convenção sobre Imprescritibilidade dos crimes de guerra e de lesa humanidade.

No caso Simón, a Corte enfrentou o problema da inconstitucionalidade das leis de Ponto Final e de Obediência Devida. Em 1978, o cidadão chileno Jose Poblete e sua esposa argentina Gertrudis Marta Hlaczik formavam parte do grupo Cristianos por la Liberación. Foram sequestrados pelo Exército argentino e conduzidos ao centro clandestino "El Olimpo". Foram torturados e a filha deles, de apenas oito meses, foi subtraída dos pais. Entre aqueles que participaram do sequestro, estavam Julian Simón e Juan Antonio del Cerro.

De acordo com Daniel Rafecas (RAFECAS, 2011, p. 161), o caso Simon, cuja decisão em primeira instância ocorreu em 2001, foi a primeira brecha que viria a romper a barreira da impunidade. O Ministério Público Fiscal inicialmente denunciou os réus pelo sequestro da filha do casal Poblete, Maria Claudia, uma vez que os casos de apropriação de crianças não foram citados pelas leis de impunidade. Entretanto, a Fiscalia ampliou a denúncia, por entender que havia provas suficientes que imputavam aos réus a morte do casal. A sentença foi procedente e os réus condenados. A segunda instância da Câmara Federal ratificou o entendimento pela inconstitucionalidade das leis de impunidade, o que levou a defesa de Símon e del Cerro a interpor Recurso Extraordinário a Corte Suprema.

Neste precedente, a Corte fixou que as leis - revogadas e anuladas - não poderiam ser aplicadas em virtude de o caso em pauta configurar delitos de lesa humanidade. Esta foi a grande importância desta decisão: por maioria, a Suprema Corte declarou a validade constitucional de Lei nº 25.779 - que anulou as Leis de Ponto Final e Obediência Devida e declarou sem efeito qualquer ato fundado nelas que pudessem obstar o avanço dos processos e julgamentos de responsáveis por crimes de lesa humanidade (LORENZETTI; KRAUT, 2011, p.147/148). Oito ministros votaram pela improcedência do recurso (Enrique

17 Assim como no Brasil, o Recurso Extraordinário, endereçado a Corte Suprema, passa por um juizo de admissibilidade do Tribunal inferior. Esse juízo geralmente abrange análise de pressupostos técnicos, que determinam se o recurso será enviado ao tribunal superior. Uma vez negado seu seguimento, cabe, no sistema recursal argentino, o Recurso de Hecho (ou Queja). 
Santiago Petracchi, Antonio Boggiano, Juan Carlos Maqueda, Eugenio Raul Zaffaroni e Elena I Highton de Nolasco, Ricardo Lorenzetti e Carmen Arigibay), tendo apenas um voto dissidente, o do ministro Carlos Fayt. Dos três casos paradigmáticos aqui analisados, esse foi o que obteve maior consenso entre os integrantes da Corte.

No caso Mazzeo, a Corte se pronunciou sobre a inconstitucionalidade dos indultos, concluindo que nenhum tipo de perdão pode opor-se e deixar sem efeito a persecução penal e a condenação de crimes de lesa humanidade. Em 2004, a Liga Argentina pelos Direitos Humanos ingressou com ação de inconstitucionalidade, buscando a anulação do indulto concedido, em 1989, a Santiago Omar Riveros, que era investigado por participação, junto com outros agentes das Forças Armadas, em diversos homicídios, privações ilegais de liberdade, torturas, lesões e violações de domicilio. O caso Riveros já havia sido levado a julgamento na década de 90, quando os familiares questionaram a constitucionalidade do indulto concedido a ele em 1989 (o indulto 1002, já referido) e a Corte Suprema, naquele contexto, declarara constitucional o indulto, uma vez que faculdade do Poder Executivo prevista na Constituição. Por esse motivo, a defesa de Riveros alegava que retomar o assunto seria uma violação ao princípio da coisa julgada, pois a instância superior do país já se manifestara pela constitucionalidade do indulto.

Por maioria, a Suprema Corte declarou inconstitucional os indultos, por entender que este ato de governo resultava na renúncia à verdade, à investigação, à identificação de autores e a desarticulação dos meios e recursos eficazes para evitar a impunidade, violando, assim, não só a Constituição Nacional, mas a Convenção Americana de Direitos Humanos e o Pacto Internacional de Direitos Civis e Políticos (LORENZETTI; KRAUT, 2011, p. 160-161).

\section{CONSIDERAÇÕES FINAIS}

O estudo comparativo dos casos brevemente analisados no presente artigo não foi pautado por um intuito reducionista de estabelecer quem lidou melhor com seu passado autoritário. Embora tenhamos uma tendência no Brasil de analisar o caso argentino como modelo em termos de acerto de contas, percebemos, ao longo da pesquisa (que analisa mais questões além das abordadas neste trabalho), que o caminho trilhado por nossos vizinhos também é alvo de críticas e questionamentos.

Como podemos compreender a trajetória de Brasil e Argentina a partir da metade dos anos 2000? Como foi possível que a Argentina retomasse os julgamentos interrompidos 
com as Leis de Impunidade e os Indultos enquanto no Brasil a discussão em torno da Lei da Anistia só foi retomada e levada à instância mais alta do Judiciário brasileiro em 2008? E como a compreensão dos ministros argentinos e brasileiros pode ser tão diversa se ambos países são signatários dos mesmos tratados internacionais?

Inegável que a vontade política de transformar o tema dos julgamentos dos crimes da ditadura em política de estado desempenhou um papel decisivo. Enquanto a administração de Nestor Kirschner optou por incluir a luta dos familiares e transformar a agenda no terreno da justiça, o governo Lula não só evitou o tema por muito tempo como privilegiou a dimensão reparatória, deixando em segundo plano a verdade e a justiça. Apenas no final do segundo mandato do presidente Lula e no primeiro mandato da presidenta Dilma Rousseff, o tema tomou nova direção, influenciado, entre outros motivos, pela condenação do Brasil no caso Gomes Lund na Corte Interamericana de Direitos Humanos, em 2010.

Em 10 de dezembro de 2014, dois anos e sete meses após a instauração da Comissão Nacional da Verdade (CNV) pela Lei. n. 12.528/2011, o Relatório Final foi entregue à Presidenta. Instalada em maio de 2012, a CNV foi criada para "apurar e esclarecer, indicando as circunstâncias e a autoria, as graves violações de direitos humanos praticadas entre 1946 e 1988 (o período entre as duas últimas constituições democráticas brasileiras) com o objetivo de efetivar o direito à memória e a verdade histórica e promover a reconciliação nacional. "

Após o trabalho realizado, entre muitas críticas (especialmente dos familiares de mortos e desaparecidos) e de muitas brigas internas entre os membros, a Comissão encerrou seus trabalhos deixando 29 recomendações, que visam prevenir a violação aos direitos humanos. A Comissão da Verdade, portanto, deixou claro que a extensão da anistia a agentes públicos que deram causa a detenções ilegais e arbitrárias, tortura, execuções, desaparecimentos forçados e ocultação de cadáveres é incompatível com o direito brasileiro e a ordem jurídica internacional, pois tais ilícitos, dadas a escala e a sistematicidade com que foram cometidos, constituiriam crimes contra a humanidade, imprescritíveis e não passíveis de anistia.

Passado quase um ano da entrega do Relatório, não há indicativo de que as recomendações estejam sendo cumpridas. A caracterização dos crimes cometidos durante a ditadura como crimes de lesa humanidade deu um sopro de esperança no terreno do acerto de contas com o passado. Entretanto, desde a condenação do Brasil na Corte Interamericana de Direitos Humanos, distintos órgãos judiciais nacionais a desconsideram e impedem a 
persecução penal justamente sob invocação de anistia e prescrição. Ignoram, ainda, a natureza de crime permanente do desaparecimento forçado, tipificado, à luz do direito interno, como sequestro ou ocultação de cadáver. Se a decisão da Corte Interamericana, a qual o Brasil é submetido, não impactou nas decisões dos magistrados brasileiros, não seria o relatório da Comissão da Verdade que o faria.

Se na Argentina o próprio Judiciário desempenhou papel central na modificação do entendimento sobre o uso da justiça (juntamente com organizações de direitos humanos e a Fiscalia), no Brasil atual esse papel tem sido quase exclusivo do Ministério Público Federal. Nesse sentido, é importante destacar que, segundo levantamento realizado pelo Grupo de Trabalho em Justiça de Transição, do Ministério Público Federal, que aponta importantes dados: das 9 ações ajuizadas pelo MPF em face de 22 agentes civis e militares envolvidos em crimes de lesa-humanidade cometidos durante a ditadura militar, apenas 3 se encontram com instrução em andamento; nas outras 6 ocorreu trancamento da ação penal por decisão em habeas corpus ou rejeição da denúncia, ratificada ou não posteriormente pelo tribunal correspondente. Em vários casos, o fundamento da paralisação foi justamente a Lei da Anistia. Em outros processos, foi invocada a prescrição e em outros ainda, descaracterizouse a natureza permanente do crime de desaparecimento forçado (definido no Código Penal brasileiro como sequestro ou ocultação de cadáver). Duas dessas ações referem-se especificamente a fatos da Guerrilha do Araguaia e caracterizam afronta direta ao decidido pela Corte Interamericana.

Em contraposição, na Argentina, a Procuradoria de Crimenes contra la Humanidad's , criada pela Procuración General de la Nación (o equivalente a PGR brasileira), produziu um Informe em outubro de 2014, no qual são avaliados os avanços nas causas de violações a direitos humanos cometidos durante o Terrorismo de Estado. Até aquele momento, 1.131 pessoas haviam sido processadas, das quais 559 foram condenadas, 61 absolvidas e os demais ainda estão sendo processados nas inúmeras causas que ocorrem em todo território nacional.

Muitos dos delitos ocorridos a partir do golpe de 1976, com seu saldo de desaparecimentos forçados, detenções arbitrárias em centros clandestinos de detenção, mortes, apropriação de crianças e bebês e milhares de exilados, dentre outros crimes, foram

\footnotetext{
18 ARGENTINA. Ministerio Público Fiscal. Informe sobre el estado de las causas por violanciones a los derechos humanos cometidos durante el terrorismo de Estado. Disponível em: <http://www.fiscales.gob.ar/lesa-humanidad/wp-content/uploads/sites/4/2014/10/Informe-octubre2014.pdf>. Acesso em: 30 jun. 2015.
} 
e seguem sendo julgados. Esta política de julgamentos reconhece uma forte pressão social e uma luta intensa dos organismos de direitos humanos e de muitos atores sociais, em busca da verdade, justiça e reparação. Sem as decisões da Suprema Corte analisadas na presente pesquisa, não estariam postas as condições para que se levassem adiante as investigações jurisdicionais.

Independentemente das maneiras que as sociedades brasileira e argentina lidaram - e lidam- com seu passado ditatorial, o contexto atual desses países aponta para um caminho tortuoso em busca da consolidação democrática. Apesar dos avanços analisados nesse trabalho, a Argentina pós ditatorial permanece com problemas crônicos de estabilidade política. Entretanto, a crise de 2001/2002, a mais grave da história daquele país, mostrou que apesar das dificuldades, a via ditatorial não é opção viável para a maioria da sociedade argentina. O trauma da última ditadura civil-militar, combinada com as políticas de memória e a condenação do genocídio levado a cabo pelas Forças Armadas, afastou essa possibilidade. No Brasil, por outro lado, permanece vivo um senso comum perigosamente inserido em diversas camadas sociais, de que a ditadura "não foi tão ruim". A impunidade, a ausência de reformas estruturais nas instituições pós 1988 e a uma cultura autoritária que permanece forte mesmo na democracia, fomentam a permanência dessa visão dissociada dos fatos ocorridos naquele período.

Apesar dos obstáculos e da passagem do tempo, a demanda por justiça permanece. Enquanto houver grupos de vítimas ou familiares, enquanto houver uma juventude disposta a manter viva a luta para que a impunidade e o desconhecimento sobre os crimes cometidos durante as Ditaduras de Segurança Nacional sejam superados, certamente haverá pressão para que não se esqueçam os horrores cometidos pelo Terrorismo de Estado nos países do Cone Sul. A garantia de que não haverá lei nem perdão para aqueles que cometem atos de perseguição política e que, mais cedo ou mais tarde, aqueles que cometem crimes de lesa humanidade serão levados à justiça, constitui um forte incentivo institucional visando consolidar uma democracia plena, onde os direitos humanos sejam respeitados e efetivados. Para isso, entretanto, é preciso não esquecer, contar às novas gerações o que ocorreu naquele período e modificar a sociedade, que permanece naturalizando práticas autoritárias e violentas. 


\section{REFERÊNCIAS}

\section{Documentos Oficiais - Legislação e Jurisprudência}

ARGENTINA. Ley de Punto Final. Disponível em: http://www.derechos.org/ddhh/arg/ley/final.txt. Acesso em 30.07.2015.

ARGENTINA. Ley de Obediencia Debida. Disponível em: http://www.derechos.org/ddhh/arg/ley/ley23521.txt. Acesso em 30.07.2015.

BRASIL. Lei n. 6.683, de 28 agosto de 1979. Concede anistia e dá outras providências. Disponível em: <http://www.planalto.gov.br/ccivil_03/leis/L6683.htm>. Acesso em 30.07.2015.

CORTE SUPREMA DE JUSTICIA DE LA NACIÓN ARGENTINA. Fallo Arancíbia Clavel (Causa n. 259) disponível em:<https://www.mpf.gov.ar/Institucional/UnidadesFE/Arancibia-Clavel-CSJN.pdf >. Acesso em 30.07.2015.

CORTE SUPREMA DE JUSTICIA DE LA NACIÓN ARGENTINA. Fallo Sìmon, disponível em: <http://www.mpf.gob.ar/lesa/jurisprudencia/fallo-simon-julio-hector-yotros-s-privacion-ilegitima-de-la-libertad/> . Acesso em 30.07.2015.

CORTE SUPREMA DE JUSTICIA DE LA NACIÓN ARGENTINA. Fallo Mazzeo, disponível em $<$ http://www.csjn.gov.ar/jurisp/jsp/fallos.do?usecase=mostrarDocumento\&falloId $=1951$ $>$. Acesso em 30.07.2015.

SUPREMO TRIBUNAL FEDERAL. ADPF N. ${ }^{\circ}$ 153. Disponível em $<$ http://www.stf.jus.br/portal/processo/verProcessoAndamento.asp?incidente $=2644116$ >. Acesso em 30.08.2013.

\section{REFERÊNCIAS BIBLIOGRÁFICAS}

AGEITOS, S. 2011. Historia de la impunidad: las actas de Videla, los indultos de Menem y la reapertura de los juicios. Buenos Aires: Adrian Hidalgo.

ALVES, M. 1987. Estado e Oposição no Brasil (1964-1984). 4. ed. Petrópolis: Vozes.

ANDREOZZI, G. (Org.). 2011. Juicios por crimines de lesa bumanidad en Argentina. Buenos Aires: Atuel.

BARRERA, L. 2012. La Corte Suprema en escena: una etnografía del mundo judicial. Buenos Aires: Siglo Venintiuno.

DREIFUS, R 1981. 1964: A conquista do Estado. Ação Política, poder e golpe de classe. Petrópolis: Vozes.

FERREIRA, J; GOMES, A. 2014. 1964: o golpe que derrubou um presidente, pôs fim ao regime democrático e instituiu a ditadura no Brasil. Rio de Janeiro: Civilização Brasileira. 
FICO, C; ARAUJO, M; GRIN, M. (Org.). 2012. Violência na História: memória, trauma e reparação. Rio de Janeiro: Ponteio.

GOMES, L; MAZZUOLI, V (Org.). 2011. Crimes da ditadura militar: uma análise à luz da jurisprudência atual da Corte Interamericana de Direitos Humanos: Argentina, Brasil, Chile, Uruguai. São Paulo: Revista dos Tribunais.

LANZILOTTA, S..; FEIJÓO, L. 2014. Justicia y Dictadura: Operadores del plan cívico-militar en Argentina. Buenos Aires: Ediciones del CCC.

LORENZETTI, R; KRAUT, A. 2011. Derechos humanos: justicia e reparación. La experiencia de los juicios en la Argentina. Crimines de Lesa Humanidad. 2. ed. Buenos Aires: Sudamericana.

NOVARO, M. 2006. Historia de la Argentina contemporânea. De Perón a Kirchner. Buenos Aires: Edhasa.

; PALERMO, V. 2007. A ditadura militar argentina 1976-1983. Do golpe de estado à restauração democrática. São Paulo: Universidade de São Paulo.

PEGORARO, J. 2011. A política na Corte: uma análise da forma de escolha dos Ministros do Supremo Tribunal Federal. Porto Alegre. Dissertação (Mestrado em Ciência Política) - Programa de Pós-Graduação em Ciência Política da UFRGS.

RAFECAS. D. La reapertura de los procesos judiciales por crimines contra la humanidad en Argentina. In: ANDREOZZI, Gabriela (organizadora). Juicios por crimines de lesa humanidad em Argentina. Buenos Aires: Atuel, 2011.

SILVA FILHO, J. 2015. Justiça de Transição: da ditadura civil-militar ao debate justransicional. Direito à memória e à verdade e os caminhos da reparação e da anistia no Brasil. Porto Alegre: Livraria do Advogado.

VENTURA, D. 2011. A interpretação judicial da Lei da Anistia brasileira e o Direito Internacional. In: A anistia na era da responsabilização: O Brasil em perspectiva nacional e comparada. Brasília: Ministério da Justiça, Comissão da Anistia: Oxford University, Latin America Centre.

VIEIRA, O. 2012. Supremo Tribunal Federal: jurisprudência política. São Paulo: Malheiros Editora. 